\title{
A TEORIA E A PRÁTICA PEDAGógICA dO ESTÁGIO SUPERVISIONADO: ESTUDO DE CASO
}

\author{
Irlan da Silva FERREIRA ${ }^{1}$ \\ Dalila Regina Mota de MELO ${ }^{2}$ \\ Francisco Pereira da SILVA JÚNIOR ${ }^{3}$ \\ Israel Vieira ROCHA ${ }^{4}$ \\ Francineide Pereira SILVA ${ }^{5}$
}

\author{
${ }^{1}$ Licenciado em Ciências Agrárias - UEPB/CAMPUS IV. irlan_darksilva@ @otmail.com \\ ${ }^{2} \operatorname{Prof}^{\mathrm{a}} \mathrm{Dr}^{\mathrm{a}}$ do departamento de Agrárias e Exatas - UEPB - Campus IV. dalilaregina @ hotmail.com \\ ${ }^{3}$ Licenciando em Ciências Agrárias - UEPB/CAMPUS IV. junior.leaozinho@ hotmail.com \\ ${ }^{4}$ Licenciando em Ciências Agrárias - UEPB/CAMPUS IV. rochaisrael@ outlook.com \\ ${ }^{5}$ Profa. Me. do departamento de Letras e Humanas - UEPB - Campus IV. rochafranci@ hotmail.com
}

Recebido em: 11/11/2014 - Aprovado em: 04/06/2015 - Disponibilizado em: 15/07/2015

\begin{abstract}
RESUMO
O Estágio Supervisionado é a ocasião essencial para que o aluno de licenciatura possa fazer a conexão entre teoria e a prática. Deste modo, objetivou-se com este trabalho descrever e analisar a experiência do Estágio Supervisionado I e Estágio Supervisionado II, do curso de licenciatura Plena em Ciências Agrárias, da Universidade Estadual da Paraíba Campus IV. As atividades foram desenvolvidas com alunos do ensino fundamental de uma escola pública do município de Catolé do Rocha- PB, no segundo semestre de 2012 e primeiro semestre de 2013. As etapas do estágio se configuraram em observação e intervenção, ou seja, vivenciando a prática pedagógica. Assim sendo, o Estágio Supervisionado é um instrumento de obtenção de um mundo novo, num ponto de vista crítico e esclarecedor. Vivenciando experiências inovadoras, trazendo a realidade da prática e do cotidiano escolar. Por sua vez, sendo este o eixo articulador entre teoria e prática, como uma unidade indissociável entre ensino e pesquisa. Portanto, para uma melhor formação acadêmica é necessário ter o contato direto com a escola e a sala de aula, de maneira que a prática do estágio observe simultaneamente os processos de cada área do ensino.
\end{abstract}

Palavras-chave - Vivência escolar. Observação. Intervenção.

\section{THEORY AND PRACTICE OF SUPERVISED TEACHING: A CASE STUDY}

\begin{abstract}
The Supervised Apprenticeship is the essential occasion so that the degree student can make the connection between theory and the practice. This way, it was aimed at with this work to describe and to analyze the experience of the Supervised Apprenticeship I and Supervised Apprenticeship II, of the course of Full degree in Agrarian Sciences, of the State University of Paraíba - Campus IV. The activities were developed with students of the fundamental teaching of a public school of the municipal district of Catole do Rocha - PB, in the second semester of 2012 and semester first of 2013. The stages of the apprenticeship were configured in observation and intervention, in other words, living the pedagogic practice. Like this being, the Supervised Apprenticeship is an instrument of obtaining of a new world, in a critical point of view and enlightening. Living innovative experiences, bringing the reality of the practice and of the daily school. For your time, being this the axis articulation between theory and practice, as an unit inseparable among teaching and he/she researches. Therefore, for a better academic formation it is necessary to have the direct contact with the school and the class room, so that the practice of the apprenticeship observes the processes of each area of the teaching simultaneously.
\end{abstract}

Keywords - School existence. Observation. Intervention. 


\section{INTRODUÇÃO}

O Estágio Supervisionado (ES) é uma exigência da Lei de Diretrizes e Bases da Educação Nacional ( $\mathrm{n}^{\circ}$ 11.788/08). Sendo necessário para a formação profissional do aluno a fim de adequar essas formações das expectativas do mercado de trabalho onde haverá atuação do licenciado.

O Estágio observador realizado no primeiro estágio, na formação de professores é um dos aspectos importantes para estudos que revelam suas dificuldades e seu potencial, dentro da sala de aula, o Estágio Supervisionado convenha a ser o primeiro contato com professores e alunos gerando transformações na vida dos profissionais. "O estágio é o eixo central na formação de professores, pois é através deles que o profissional conhece os aspectos indispensáveis para a formação da construção da identidade e dos saberes do dia-a-dia" (PIMENTA; LIMA, 2004).

De acordo com Santos (2005) o Estágio Supervisionado, junto com as disciplinas teóricas desenvolvidas na licenciatura, é um espaço de construções significativas no processo de formação de professores, contribuindo com o fazer profissional do futuro professor.

A intervenção, que é proporcionada no Estágio Supervisionado II está vinculada à ideia de um estágio voltado para o atendimento à comunidade o qual deverá proporcionar o engajamento do estagiário na realidade, para que possa perceber os desafios que a carreira do magistério tem a oferecer, sendo assim, pode-se refletir maduramente sobre a profissão que será assumida, pois envolvem situações reais vividas interligando o saber e como fazer.

Na colocação escola-trabalho, pode-se perceber a importância do Estágio Supervisionado como elemento capaz de desencadear a relação entre pólos de uma mesma realidade e preparar mais convenientemente o aluno estagiário para o mundo de trabalho.

Segundo Piconez e Fazenda (2006), o Estágio Supervisionado deve ser considerado um instrumento fundamental no processo de formação do professor, contribuindo para a formação de sua consciência política e social, unindo a teoria à prática.

Portanto, é o Estágio Supervisionado uma parte importante da relação trabalhoescola, teoria-prática, e eles podem representar, em outra medida, o elo de articulação orgânico com a própria realidade.

O Estágio Supervisionado deve ser um agente contribuidor na formação do professor, caracterizando-se como objeto de estudo e reflexão. Ao estagiar o futuro professor passa enxergar a educação com outro olhar, procurando entender à realidade da escola e o comportamento dos alunos, dos professores e dos profissionais que a compõem, procurando meios para intervir de forma positiva. 
O Estágio Supervisionado é o momento adequado para que o estagiário desenvolva competências transformando o seu estágio em uma atividade reflexiva; visando uma educação de qualidade; buscando cumprir o seu real papel de professor, o de tornar a escola cidadã, promotora da transformação social. É o momento de começar a refletir sobre sua ação de construção e reconstrução da aprendizagem enquanto aprendiz inserido agora em uma formação continuada, necessária para realimentação do ciclo ação reflexão - ação. Pode-se constatar esta preocupação em Pimenta (2005, p.121), quando ele diz que "o Estágio Supervisionado é visto como atividade teórica instrumentalizadora da práxis do futuro professor."

É, portanto, o estágio, uma importante parte integradora do currículo, a parte em que o licenciado vai assumir pela primeira vez a identidade profissional e sentir na pele o compromisso com o aluno, com sua família, com sua comunidade e com a instituição escolar, que representa sua inclusão civilizatória, com a produção conjunta de significados em sala de aula, com a democracia com o sentido de profissionalismo que implique competência fazendo bem o que nos compete (ANDRADE, 2005).

Em suma, compreende-se que o referido estágio seja importante para instrumentalizar o estudante de Licenciatura
Plena em Ciências Agrárias e sua futura profissão pedagógica, familiarizando com a prática de sala de aula convivendo com alunos e professores em ambiente escolar, encontrando aclamações, desafios e dificuldades, sobretudo nos fazem crer que diante da tamanha responsabilidade nós preferimos acreditar que entre muitos há alguém ou algum que tem interesse de mudar esse cenário educacional.

Nesse sentido, objetivou-se com este trabalho descrever e analisar as atividades do Estágio Supervisionado I e Estágio Supervisionado II do curso de licenciatura Plena em Ciências Agrárias da Universidade Estadual da Paraíba - Campus IV.

\section{CARACTERIZAÇÃO INSTITUIÇÃO}

As atividades de observação da comunidade escolar e intervenção em sala de aula foram realizadas no Centro de Ensino Fundamental Luzia Maia, localizada na Rua Adolfo Maia, 1.152, no bairro Luzia Maia, em Catolé do Rocha-PB, especificamente no alto sertão.

A escola pertence à rede pública municipal de ensino e estar vinculada a prefeitura municipal de Catolé do Rocha. Funcionando atualmente com a autorização da Resolução do Conselho Estadual de Educação $\mathrm{N}^{\mathrm{o}}$ 115/96 de 26/09/1996, que renova a autorização para o funcionamento da 
educação infantil (Pré-escola) e Ensino Fundamental de 09 (nove) anos.

A escola surgiu da necessidade de atender alunos carentes, pois os estabelecimentos de ensino, já existentes no município, não comportavam a demanda da comunidade catoleense já na década de 1960. Assim, em 26 de fevereiro de 1970, esta instituição foi inaugurada por Benedito Alves Fernandes.

A escolha do nome foi uma homenagem a Dona Luzia Maia, uma das primeiras Professoras da cidade, mãe de Arione Maia e proprietário do terreno onde se localiza a Escola e os bairros Luzia Maia e Natanael Maia. Este último foi uma homenagem ao Sr. Natanael Maia que era farmacêutico e esposo de Dona Luzia Maia.

\subsection{Estrutura física da escola}

A escola de Ensino Fundamental Luzia Maia funciona durante três turnos, assim distribuídos: pela manha e à tarde, atende crianças e adolescentes de educação infantil e de $1^{\circ}$ ao $9^{\circ}$ ano e à noite, atende aos alunos do EJA (Educação de Jovens e Adultos).

A escola é constituída de 30 salas de aula, amplamente arejadas, com iluminação adequada, pois são ladeadas por corredores e cada uma delas dispõe de 2 (duas) janelas de um lado e a porta do outro. Tem ainda, 2 (dois) ventiladores de teto. Cada sala de aula possui em média 40 (quarenta) carteiras, o suficiente para receber os alunos nos 3 (três) turnos. Os quadros são de giz e todos bem fixados nas paredes, quase todas as salas dispõem de um birô e cadeira para o professor.

Nas salas de aula da Educação Infantil existem armários e prateleiras de aço que servem para organizar o material das crianças durante o período de aula. Nessas salas ainda são colocadas garrafas térmicas com água para melhorar acomodação das crianças. Além das salas de aula, conta-se com 2 (dois) galpões cobertos que são utilizados nos eventos realizados na Escola. Também tem uma quadra de esporte com palco, banheiros e arquibancadas - em etapa final de sua construção.

Existe uma sala de vídeo e um laboratório de informática que funciona em sala climatizada e com dupla função dispondo de 10 (computadores) conectados a internet, além com alguns recursos audiovisuais como TV, DVD, micro - system, filmadora e 2 (dois) datas show com tela de projeção.

A escola dispõe de uma biblioteca que funciona pela manhã e à tarde e tem bom acervo, conta-se com aproximadamente com 800 exemplares, disponibilizados para suprir a necessidade do alunado, professores e toda comunidade escolar. 
2.2 Corpo docente e funcional da escola

$\mathrm{O}$ atual quadro de funcionário da escola conta com 82 servidores concursados em regime estatutário com carga horária mínima de 30 horas e máxima de 40 e apenas um membro nomeado pelo gestor municipal.

O corpo docente está dividido por segmentos, como por exemplo, 39 professores lecionam no ensino fundamental $\mathrm{I}$ e II, cumprindo um carga horária semanal de 30 horas segundo o Plano de Cargos, Carreiras e Salários do município de Catolé do Rocha. A instituição conta também com 4 Supervisoras Educacionais, uma Psicopedagoga, uma Psicóloga, uma Diretora, sendo uma geral e uma professora que atua como adjunta. A escola conta ainda com 01 (um) funcionário administrativo e 10 (dez) auxiliares de serviços gerais.

\subsection{Corpo discente da escola}

A escola possui atualmente 1735 (mil setecentos e trinta e cinco) alunos matriculados, compreendendo um publico bastante diversificado, iniciando-se por crianças a partir dos 04 (quatro) anos de idade, sendo que o ensino infantil Pré I pela manhã a turma é formada por 33 (trinta e três) alunos, já o Pré II pela manhã conta com 47 (quarenta e sete) alunos, e pela tarde conta com 17 (dezessete) alunos. O EJA por sua vez é formado por 3 (três) turmas no período da noite sendo totalizado 52 (cinquenta e dois) alunos nas três turmas. Já o ensino fundamental que corresponde desde do $1^{\circ}$ ao $9^{\circ}$ ano, está subdividido em 47 turmas atendendo um total de 1563 (mil quinhentos e sessenta e três) alunos nos turnos da manhã e tarde, resultando em uma média de 33 alunos por sala de aula.

\subsection{O Projeto Político Pedagógico}

Algo de tamanha importância para uma instituição é o Projeto PolíticoPedagógico (PPP) que é o responsável pelo que entra e sai na escola, todo o funcionamento. Assim sendo, o PPP determina a identidade da escola, indicando caminhos para o ensino de qualidade.

Pensar em Projeto Político Pedagógico para qualquer escola pressupõe que os educadores tenham um espaço onde possam se manifestar que o processo da escola e suas experiências acumuladas sejam refletidos. Que haja uma definição anterior sobre qual a concepção de Projeto Político Pedagógico será utilizada pelo grupo.

No Centro de Ensino Fundamental Luzia Maia há um Projeto PolíticoPedagógico, elaborado pelos supervisores, que os apontam como principais problemas escolares, que é o atraso dos alunos em relação a leituras a dificuldade de apresentar trabalhos de sua autoria, aonde chega a ser motivo de discussões entre alunos e 
professores, ocasionando uma distorção entre idade e série, havendo uma mistura de idade dentro das salas.

Podemos observar também que há certa dificuldade em participação dos alunos na sala de aula. O Projeto Político Pedagógico do Centro de Ensino Luzia Maia aborda uma proposta pedagógica que busca desenvolver um trabalho participativo, tanto na sala de aula, quanto com a comunidade, oferecendo sempre um ensino de qualidade, dando assistência aos professores nos planejamentos, os ajudando a modificar algo em sua metodologia de ensino. Incentivando os alunos a se interessarem pela leitura com produções de textos por meio de concursos de redação, realização de palestras, dos quais orientam os professores, como também os pais, para que formem seus filhos na ética.

Os conteúdos para serem desenvolvidos na sala de aula, devem ser discutidos pelos professores e supervisores para serem analisados e planejados, visando um melhoramento no seu método de ensino para ser transmitido. A metodologia descrita pelo Projeto Político Pedagógico, para que seja desenvolvida pelos professores em sala de aula e avaliar os métodos usados, como ajuda dos alunos para assim melhorar o processo de ensino e aprendizagem do Centro de Ensino.

\section{REVISÃO DE LITERATURA}

\subsection{Estágio Supervisionado}

De acordo com a legislação vigente, Lei 11.788 de 25/09/2008, o estágio é conceituado como o "ato educativo escolar supervisionado, desenvolvido no ambiente de trabalho, objetivando a preparação para o mercado de trabalho do estudante de licenciatura", promovendo aprendizagem social, profissional e cultural, através da sua participação em atividades de trabalho, vinculadas à sua área de formação acadêmicoprofissional. Fundamenta-se em um “compromisso formalizado entre o estagiário, a instituição de ensino e a empresa com base em um plano de atividade que materializa a extensão ao ambiente de trabalho do projeto pedagógico desenvolvido nas disciplinas do currículo escolar.

Entretanto, o Estágio Supervisionado é uma das mais eficientes formas de propiciar ao estudante a complementação profissional, pois o coloca em contato direto com a realidade da indústria, com o ambiente real de trabalho e com os mais diversos problemas técnicos. Neste período, também o aspecto humano-social é aprimorado, em face do consequente contato com problemas sociais e culturais, que se apresentam no ambiente de trabalho.

Para realização do Estágio na Universidade Estadual da Paraíba (UEPB), a 
documentação exigida é um Termo de Compromisso de Estágio (Instrumento Jurídico de que trata a Lei $\mathrm{n}^{\mathrm{o}} 11.788$, de 25/09/08) devidamente preenchido com os dados da fase do Estágio Supervisionado a ser realizado, da instituição de ensino, empresa concedente e do estagiário que realizará o processo e assinado por todos os envolvidos. É exigido também um Plano de Estágio Obrigatório, onde o aluno descreve todas as atividades que serão realizadas durante o período do estágio assinado pelo estagiário, professor orientador da instituição de ensino concedente e o professor supervisor da instituição de ensino da UEPB (FREITAS, 2013).

De acordo com a RESOLUÇÃO/UEPB/CONSEPE/XX/2013, que regulamenta e define carga horária e ementas dos componentes curriculares Estágio Supervisionado nos cursos de Licenciatura da UEPB, no Art. $5^{\circ}$ diz que a carga horária do componente curricular Estágio Supervisionado será de 400 horas, sendo indispensável para obtenção do diploma, o Estágio Supervisionado no curso de licenciatura plena em Ciências Agrárias pertencente ao Departamento de Agrárias e Exatas, localizado no Centro de Ciências Humanas e Agrárias (CCHA) no Campus IV da UEPB na cidade de Catolé do Rocha, possui 420 horas distribuídas em quatro ES (105 horas em cada) (FREITAS, 2013).
O Estágio Supervisionado I e o Estágio Supervisionado II são cumpridos em escola pública municipal e estadual. No Estágio Supervisionado I é realizado a observação da vivência da realidade escolar e planejamento e no Estágio Supervisionado II a intervenção. A disciplina observada e ministrada pelos estagiários é das Ciências Naturais (Ciências). Os assuntos abordados na disciplina de Ciência trabalham o meio ambiente incluso no cotidiano dos alunos. Já o Estágio Supervisionado III e o Estágio Supervisionado IV são realizados na Escola Agrotécnica do Cajueiro que faz parte do CCHA. O Estágio Supervisionado III é realizado observação da vivência da realidade escolar e planejamento do Ensino Médio Integrado e profissionalizante no curso técnico em Agropecuária e no Estágio Supervisionado IV a intervenção. As disciplinas observadas e ministradas pelos estagiários são das Ciências Agrárias (FREITAS, 2013).

\subsection{Formação de professores}

As reformas educacionais trouxeram muitas alterações para a vida dos professores, bem como para a sua formação. A carreira continua apresentando as dificuldades existentes há muito tempo, ou seja, uma profissão é desvalorizada em virtude das dificuldades encontradas ao longo do percurso. 
A escola, como local de trabalho dos professores, assume o poder de reforma educacional, tendo em vista ser o espaço de formação docente, podendo assim praticar a coletividade do trabalho.

Segundo Elia (1995) a Formação de Professores é uma oportunidade que o professor volta a refletir sobre seus conceitos e teorias usando a sua própria experiência seguida de sua prática pedagógica. Nessa perspectiva Rodrigues (2003) afirma que a Formação Inicial de professores apresenta duas macros dimensões: uma responsável por rigorosa formação científica e a outra responsável por imersão exigente apoiada no contexto real de trabalho. Este ainda cita que "a profissão de professor se aprende na escola e na sala de aula e é um processo longo de uma vida".

Para Queiroz (2001) “o professor tem a função de fazer com que os alunos adquiram certo saberes, presentes, em geral, nas matérias escolares, participando, além disso, da educação no sentido mais amplo, preparando-o para a vida em sociedade". De acordo com Pimenta e Lima (2004) “o professor é um profissional que tem um papel de fundamental importância no desenvolvimento pessoal e intersubjetivo do aluno, sendo um facilitador de seu acesso ao conhecimento".

Os trabalhos dos educadores normalmente estão de acordo com o Projeto Político Pedagógico do curso, estes deverão construir parcerias com as escolas e setores da comunidade, orientar Trabalhos de Conclusão de Curso (TCC), pesquisas de Iniciação Científica e publicá-los regularmente (MIZUKAMI, 2005). Isto é, os professores devem orientar acompanhar e supervisionar a prática profissional dos alunos. Em conformidade com Rodrigues (2003) “o professor precisa que lhe seja dada oportunidade de se vê ao espelho, de se ver em situação, pela medição da observação de outros, de modo a poder fazer aproximações sucessivas, numa relação pratico teórico".

$\mathrm{Na}$ prática os alunos aprendem observando os professores mais experientes. "Os formadores são práticos, assumidos como modelos e a formação faz prevalecer os mecanismos de acomodação mais do que de assimilação" (RODRIGUES, 2003). O mesmo autor ainda afirma que a prática é considerada como a mais importante e a mais poderosa componente dos programas de formação de professores.

Segundo Mizukamin (2005) "a prática não supre o domínio dos conteúdos específicos de forma satisfatória e não oferece base de conhecimento que o professor necessita para ensinar, assim como para continuar seu processo de aprendizagem de desenvolvimento profissional". Por sua vez, através da prática é possível que os alunos obtenham um amplo desenvolvimento, além de uma interação entre professor e alunos. Mas essa interação, segundo Lombardi 
(2005), entre professor/aluno, e aluno/ conteúdo depende da capacidade do professor de refletir e criar estratégias para o desenvolvimento do aluno.

\section{DESCRIÇÃO DAS ATIVIDADES}

O Estágio Supervisionado I e o Estágio Supervisionado II foram realizados no Centro de Ensino Fundamental Luzia Maia, no segundo semestre de 2012 e primeiro semestre de 2013, respectivamente.

\subsection{Observações}

As atividades de observações realizadas durante o Estágio Supervisionado I, as quais nós estagiários observamos o funcionamento da escola, um instituto público municipal, localizada no município de Catolé do Rocha, PB.

Em conformidade com Ghedin et al. (2008) é possível verificar o cotidiano da escola através da observação, objetivando proporcionar ao estagiário a identificar os pontos fortes e os problemas da escola, que transcorrem todos os aspectos e setores da realidade escolar.

Durante o período de observação constatamos que a escola possui aproximadamente 30 salas de aula, com capacidade para comportar quarenta alunos por sala, e que a mesma possui um bom espaço físico, entretanto com alguns equipamentos e instalações que não estão em funcionamento ou estão com defeitos e sem uso.

Um dos fatores que pode exercer influência sobre a qualidade da educação dos discentes é a infra-estrutura escolar, como por exemplo: prédios e instalações adequadas, existência de biblioteca escolar, espaços rotativos e laboratórios, acesso a livros didáticos, materiais de leitura e pedagógicos, relação adequada entre o número de alunos e o professor na sala de aula e maior tempo efetivo de aula, possivelmente melhorem o desempenho do aluno (SÁTYRO; SOARES, 2007)

Também foram realizadas observações em sala de aula na disciplina de Ciências. Ministrada pelo professor Ney Robson. De forma geral, o referido professor apresentou coerência nos assuntos descritos na grade curricular da disciplina. As observações foram realizadas na turma do $8^{\circ}$ ano $\mathrm{C}$, sendo composta por 20 alunos, com idades variando entre 14 e 16 anos, nenhum com deficiência, tendo 2 alunos repetentes.

$\mathrm{O}$ assunto trabalhado foi alimentos: a importância dos alimentos na nossa vida, pois é uma fonte de energia. Esse assunto foi bem questionado, e surgiram muitas dúvidas por parte dos alunos. O professor deu o conteúdo, passou exercícios, marcou avaliação e apresentação de trabalhos. O mesmo utilizava sempre o livro didático nas suas aulas. 
Durante as aulas observadas constatamos que quando os alunos não colaboravam com as aulas o professor se comportava de forma alterada, gritando, reclamando e cobrando interesse dos mesmos. Tirando alguns momentos de estresse por parte dos alunos, observou-se um bom comportamento e organização por parte deles, mostrando ser bem interessados e estudiosos.

A observação é um meio tradicional para se chegar ao conhecimento, pois não é um fato facilmente realizável. Nela não entram apenas as imagens que nossos olhos conseguem ver, outra parte, importante é a constituição do nosso cérebro a dependência da nossa cultura, conhecimento e expectativas.

$\mathrm{O}$ processo ensino aprendizagem do Centro de Ensino Fundamental Luzia Maia caracteriza-se por uma sistemática de atividades diversas desenvolvida em etapas com a participação da equipe pedagógica professores e alunos que procuram estudar os métodos para seguir um determinado processo com a finalidade de captar e analisar as características dos vários métodos disponíveis para melhorar o seu processo ensino aprendizagem.

\subsection{Intervenções}

As atividades de intervenção em sala de aula vivenciada durante o Estágio Supervisionado II foram realizadas na turma do $8^{\circ}$ Ano $\mathrm{C}$, na disciplina de Ciências, pertencente ao professor Ney Robson. O conteúdo trabalhado foi sobre o sistema circulatório: Que é responsável por conduzir elementos essenciais para todos os tecidos do corpo: oxigênio para as células, hormônios (que são liberados pelas glândulas endócrinas) para os tecidos, condução de dióxido de carbono para sua eliminação nos pulmões, coleta de excretas metabólicos e celulares, entrega desses rejeitos nos órgãos excretores, como os rins. Além disso, apresenta importante papel no sistema imunológico de defesa contra infecções, na termorregulação (acima da temperatura normal, efetua a vasodilatação dos vasos periféricos e, abaixo dela, produz vasoconstrição periférica). $\mathrm{O}$ transporte de nutrientes desde os locais de absorção até as células dos diferentes órgãos também é realizado por este sistema. De modo geral, o sistema circulatório mantém as células em condições adequadas para que consigam sobreviver e desempenhar suas funções individuais da melhor maneira, portanto permite a manutenção da homeostase.

A aula foi iniciada com várias perguntas feitas aos alunos sobre "O Sistema Circulatório". Com o objetivo de identificar o conhecimento prévio desses sobre o tema, além de problematizar a questão. Neste primeiro momento, houve pouca interação por parte dos alunos, que estavam um pouco intimidados. Ao término das aulas, foi 
solicitado que realizassem um exercício sobre o assunto abordado na referida aula. Os recursos didáticos utilizados foram o Livro Didático, quadro e pincel. Todas as aulas ministradas foram utilizadas os mesmos recursos e métodos de avaliação.

Entretanto, as aulas de Ciências ministradas durante as intervenções, foram planejadas seguindo as orientações de Brasil (1998), quando ressalta que o professor deve planejar cada tema, selecionando problemas, que correspondem às situações interessantes a interpretar.

Durante a intervenção é uma forma de ter uma prática, avaliando esta prática e reformulando-a. Desta forma, na sala de aula com atividades e entre o professor e o estagiário há uma troca de informação quando o professor (a) interfere com ajuda, dando informações sobre as dificuldades da classe, fazendo com que possamos planejar em cima das dificuldades encontradas. Porém muitas vezes o próprio estagiário é quem detecta muitos problemas presentes na sala de aula, sejam eles falhas na aplicação da teoria ou muitas vezes a prática do ensino adotado não compreendida pelo aluno.

Segundo Pimenta (2001), “o período da regência, promove ao acadêmico, uma real aproximação da realidade profissional que o aguarda ao término da sua formação. É de fundamental importância esse processo da formação docente, pois a partir dessa experiência os licenciandos se percebem como futuros professores, enfrentando pela primeira vez o desafio de conviver, falar e ouvir, com linguagens e saberes diferentes daqueles de seus campos específicos".

Todas as etapas do estágio se configuraram como momentos de coleta de dados que serviram para nós estagiários refletirmos sobre nossa prática pedagógica. As situações vivenciadas subsidiaram discussões que possibilitaram a nós futuros professores assumirmos com autonomia os processos educativos, permitindo este se perceber enquanto agente capaz de intervir no sistema e na estrutura da escola.

\subsection{Planejamento das aulas}

As aulas foram planejadas juntamente com o professor titular da disciplina, o planejamento teve como base o livro didático como fonte de conhecimento pra a preparação de uma melhor forma de transição do conhecimento para os alunos, com o livro e a ajuda do professor, pode-se fazer um bom plano de aula, e uma boa metodologia de ensino obtido com a observação da metodologia do professor, onde todos os aspectos dos assuntos que seriam abordados fossem transmitidos de uma forma satisfatória. As aulas elaboradas obtiveram o resultado esperado em função de fixação do conteúdo abordado e aprendizagem do assunto. 


\section{RELAÇÕES INTERPESSOAIS}

\subsection{Professor - Aluno}

A capacidade das pessoas de se relacionar depende das experiências que vivem, e as instituições educacionais são uns dos lugares preferenciais, para estabelecer vínculos e relações que condicionam e definem as próprias concepções pessoais sobre si mesmo e sobre os demais temas sugeridos durante o período de intervenção em sala de aula, dando ênfase as Ciências.

O papel do professor de ensino tem priorizado as capacidades cognitivas, mas nem todos, e sim aquelas que se tem considerado mais relevantes e que, como sabemos, correspondem à aprendizagem das disciplinas ou matérias tradicionais.

Mediante a situação encontrada por nós estagiários, foi pouca a participação do professor perante o período de intervenção em sala de aula, pois o mesmo estava de licença médica e isso foi uma das dificuldades encontradas durante as aulas ministradas em sala, pois o comportamento do alunado é realmente de suma importância para desenvolver o assunto sugerido para trabalhar em sala, onde eles deveram participar e buscar interagir junto ao professor contribuindo para a construção do saber.

Freire (1996, p. 159-160) afirma que:

Não é certo, sobretudo do ponto de vista democrático, que serei tão melhor professor quanto mais severo, mais frio, mais distante e "cinzento" me ponha nas minhas relações com os alunos [...] A afetividade não se acha excluída da cognoscibilidade. $\mathrm{O}$ que não posso obviamente permitir é que minha afetividade interfira no cumprimento ético de meu dever de professor no exercício de minha autoridade. Não posso condicionar a avaliação do trabalho escolar de um aluno ao maior ou menor bem querer que tenha por ele.

Outro reflexo desse aspecto (excesso de afetividade), mas sob um prisma mais direcionado à superproteção, geralmente pode ser observado em salas de ensino fundamental da quinta série: crianças indisciplinadas, inquietas, por vezes, arrogantes e revoltadas.

O contexto escolar é parte integrante dos conhecimentos dos professores e inclui, entre outros, conhecimentos sobre os estilos de aprendizagem dos alunos, seus interesses, necessidades e dificuldades, além de um repertório de técnicas de ensino e de competências de gestão de sala de aula (SBEM, 2008).

O professor responsável pelo Estágio Supervisionado poderá fazer dessas experiências um excelente material de estudo, analisando e fazendo leituras, junto com os alunos-estagiários, além de planejar ações de intervenção pedagógica a fim de propiciar possíveis mudanças no quadro educacional.

A relação do professor em sala de aula é de se esperar, como sendo uma das melhores possíveis, tendo em vista ser um dos mediadores do conhecimento, precisando está sempre pronto para sanar qualquer situação encontrada. 
Um ingrediente essencial para que se tenha um bom relacionamento professoraluno é o diálogo, pois intensifica a interação das partes envolvidas num processo de ensino aprendizado. A forma como o professor age coopera para que o aluno se sinta mais receptivo e menos apreensivo. O educador deve estar sempre buscando uma forma de melhorar o relacionamento.

\subsection{Aluno-Aluno}

A relação aluno-aluno foi razoável, pois se tratava de turmas cheias, contendo a mesma de diversas culturas, etnias, classes sociais e de pensamentos e que os tímidos eram os que menos participavam das aulas.

Portanto, fica claro e evidenciado que o desenvolvimento de uma turma parte do pressuposto que a rede pública é pobre de incentivos para $\mathrm{o}$ alunado buscar $\mathrm{o}$ conhecimento, sendo um dos papéis fundamentais da universidade e dos estagiários em procurar melhores formas de transmitir e incentivar ao seu alunado o real valor do saber.

Segundo Masseto (1996), “o sucesso (ou não) da aprendizagem está fundamentado essencialmente na forte relação afetiva existente entre alunos e professores, alunos e alunos e professores e professores".

Tornar-se um professor facilitador não é uma tarefa fácil, pois requer a quebra de paradigmas; o aprender a não desistir; a conscientização de que em uma sala de aula não há aprendizado homogêneo e imediato; que a orientação do professor, acompanhando cada passo do aluno, com a intenção de que ele, gradativamente, liberte-se e demonstre seu potencial, é fundamental; a percepção de que a formação continuada é uma necessidade, e que uma postura críticareflexiva deve fazer parte do seu dia-a-dia.

\section{CONCLUSÕES}

O Estágio Supervisionado é um instrumento de aquisição de um mundo novo, num ponto de vista crítico e esclarecedor. Vivenciar experiências até então inovadoras, nos permitiu enxergar a realidade da nossa sociedade, da educação e do sistema escolar. Sendo este o eixo articulador entre teoria e prática, como uma unidade indissociável entre ensino e pesquisa.

Diante da tamanha responsabilidade ao estagiar, mostra o quanto é importante o ato da prática, pois isso ajuda o discente a descobrir se é ou não aquilo que realmente se quer para sua vida, tudo gera uma única decisão, se continua ou para. A contribuição que o Estágio Supervisionado proporcionou serve para compreensão da ação que o educador deverá se revelar como resposta as diferentes necessidades colocadas pela realidade educacional e social. Portanto, nossa formação deverá ter como principal finalidade a consistência crítica da educação brasileira e 
o papel exercido por ela na sociedade como um todo.

Para melhorar a qualidade do ensino é preciso conhecer e poder avaliar a intervenção pedagógica dos professores, de forma que a ação avaliadora observe simultaneamente os processos individuais fazendo assim aparecer à qualidade ou não do estagiário, pois como em qualquer área de trabalho sempre virão às cobranças.

Portanto, um fator imprescindível é um bom relacionamento estabelecido entre o professor e o estagiário e aluno - aluno, pois quando é criado um vínculo entre professor estagiário e aluno-aluno, gera um ambiente de equilíbrio, onde o professor respeita o aluno como ser humano em fase de formação de conhecimentos e valores. Contudo, um dos fatores que contribuem para o sucesso da aprendizagem é a afetividade existente entre alunos e alunos, aluno e professores, professores e professores.

\section{REFERÊNCIAS BIBLIOGRÁFICAS}

ANDRADE, A. M. O estágio Supervisionado e a Práxis Docente. In: SILVA, M. L. S. F. (Org). Estágio Curricular: Contribuições para o Redimensionamento de sua Prática. Natal-RN: Editora UFRN, 2005.

\section{BRASIL. Lei no 9394/96, Lei de Diretrizes e}

Bases da Educação Nacional, de 20 de dezembro de 1996. Brasília, 1996.
BRASIL Secretaria de Educação Fundamental. Parâmetros Curriculares Nacionais: Ciências Naturais. Terceiro e quarto ciclos do ensino fundamental. Brasília, DF, 1998.

\section{ELIA, M. A formação de Professores na}

UFRJ: Uma visão Institucional, 1995.

Disponível em

<http:www.cciencia.Ufrj.br/Publicacoes/Artig os/Edubytes95/FormProfUFRJ.htm>.Acesso em 27 Nov. 2012.

FREIRE, P. Pedagogia da autonomia: Saberes necessários à prática educativa.

São Paulo: Paz e Terra, 1996.

FREITAS, M.. Importância do estágio supervisionado para a formação docente do licenciado em Ciências Agrárias. 2013. 12 f. Trabalho Acadêmico Orientado (Graduação em Ciências Agrárias) - Universidade Estadual da Paraíba, 2013.

GHEDIN, E.; LEITE, Y. U. F.; ALMEIDA, M. I. Formação de professores: Caminhos e descaminhos da prática. Brasília: Líber Livros, 2008.

LOMBARDI, R. F. Formação Inicial: Uma observação da prática docente por discurso de alunos estagiários do curso de Letra, 2005. Disponível em: <http://www. 
congresso/ed2005.puc.c/pdf/ferreira\%20lomb ardi.pdf> . Acesso em 27 Nov. 2012.

MASSETO, M. Didática: A aula como centro. São Paulo: FTD. 1996.

MIZUKAMI, M. G. N. Aprendizagem da Docência; Professores formadores. Revista E-Curriculum. São Paulo, v. 1, n.1, p. 5-12, dez. / jul, 2005 - 2006. Disponível em: <http://www.pucsp.br/ecurriculum/docs/pdf/ mizukamiartigo.pdf $>$. Acesso em 21 Jun. 2012.

PICONEZ, S. C. B; FAZENDA, I. C. A; A pratica de ensino e o estagio supervisionado. 12 ed. Campinas. SP. Papirus, 2006. p. 63-65.

PIMENTA, S. G. O Estágio na Formação de Professores: Unidade Teoria e Prática. $4^{\mathrm{a}}$ ed. São Paulo, SP, 2001.

. O Estágio na Formação de

Professores: unidade teoria e prática. São

Paulo: Cortez, 2005

PIMENTA, S. G.; LIMA, M. S. L. Estágio e

Docência. São Paulo, SP, 2004.

QUEIROZ, G. R. P. C. Processo de Formação de Professores Artistas Reflexivos de Física. Revista Cedes. Campinas, v. 22, n.74, p. 97119, Abril, 2001. Disponível em: http://www.scielo.br/scielo.php?script=sci_art text\&pid=S010173302001000100007\&lng=e s\&nrm=isso. Acesso em: 22 Jun. 2012.

RODRIGUES, N. Por uma nova escola: o transitório e o permanente na educação. $13^{\mathrm{a}}$ ed. São Paulo: Cortez, p. 51-65, 2003.

\section{SANTOS, H. M. O Estágio Curricular na} formação de professores: diversos olhares. Caxambu, MG, 2005.

SÁTYRO, N.; S, S. A Infra-estrutura das

Escolas Brasileiras de Ensino

Fundamental: Um Estudo com Base nos Censos Escolares de 1997 a 2005. Brasília, DF, 2007.

SOCIEDADE BRASILEIRA DE EDUCAÇÃO MATEMÁTICA. Subsídios para a discursão de propostas para os cursos de Licenciatura em Matemática: Uma Contribuição da Sociedade Brasileira de Educação Matemática. Disponível em: <www. prg. unicamp. br/Subformação Professores/SBEM licenciatura. Pdf >. Acesso em 16 jul 2013. 